\title{
Characterization of diethylnitrosamine-induced liver carcinogenesis in Syrian golden hamsters
}

\author{
GUO CHEN $^{1 *}$, ZHI-KAI DAI $^{*}$, RONG-GAN LIANG ${ }^{1}$, SHENG-JUN XIAO $^{2}$, \\ SONG-QING HE ${ }^{3,4}$, HAI-LU ZHAO ${ }^{2,4}$ and QING XU ${ }^{1,4}$ \\ ${ }^{1}$ Department of Pharmacology, College of Pharmacy; ${ }^{2}$ Faculty of Basic Medicine; ${ }^{3}$ Department of Surgery, \\ Faculty of Clinical Medicine; and ${ }^{4}$ Liver Disease Laboratory, Guilin Medical College, Guilin 541004, P.R. China
}

Received October 8, 2011; Accepted November 29, 2011

DOI: $10.3892 /$ etm.2011.406

\begin{abstract}
The aim of this study was to characterize hepatocarcinogenesis in diethylnitrosamine (DEN)-treated hamsters. Syrian golden hamsters $(n=36)$ were administered DEN by hypodermic injection and addition to drinking water. Morphological analyses, including light microscopy and immunohistochemistry of $\alpha$-fetal protein (AFP), were performed on liver and lung tissues. Primary cell culture and tumor transplantation were carried out to evaluate the potential application in hepatocellular carcinoma (HCC) research. From 25 to 50 weeks of treatment, liver tumors, including macronodular HCC and ascites, were found in one-third (4/12) of the animals treated with DEN. HCC was characterized by poor differentiation, frequent mitosis, AFP reaction, vessel invasion and potential application in primary cell culture and xenotransplantation. Pre-neoplastic lesions were hyperplastic nodules comprised of clear cells, bile duct proliferation, fatty metamorphosis and multilocular cysts. The DEN-treated hamsters also showed lung tumors consisting of AFP-negative, well-differentiated neoplastic cells. Characterization of DEN-induced HCC in hamsters provides insights into human hepatocarcinogenesis. This animal model has potential applications in HCC research.
\end{abstract}

\section{Introduction}

Hepatocellular carcinoma (HCC) is the sixth most common cancer and the third most common cause of cancer-related death in the world $(1,2)$. The number of new HCC cases is estimated to be 564,000 per year, including 398,000 men and 166,000 women (3). It accounts for $80 \%$ of all human liver

Correspondence to: Professor Qing Xu, Department of Pharmacology, College of Pharmacy, Guilin Medical University, North 2nd Huan Cheng Road, Guilin 541004, P.R. China

E-mail: xq5895801@163.com

*Contributed equally

Key words: diethylnitrosamine, hamster, hepatocellular carcinoma, nodular hyperplasia, lung tumor cancers, and is responsible for 0.5-1 million worldwide deaths annually (4). The rising incidence and poor prognosis of HCC cases have prompted extensive research on its pathogenesis for a better understanding of HCC development.

Toxic industrial chemicals, air and water pollutants, food additives and fungal toxins are major sources of hepatocarcinogenesis (5). Although these agents have been suspected, the molecular pathogenesis of HCC remains unclear. As an established environmental hepatocarcinogen, diethylnitrosamine (N-nitrosodiethylamine; DEN), which produces primary metabolic activation resulting in initiation of liver carcinogenesis (6) and formation of liver tumors after repeated administration, is normally used to induce liver cancer in several animal models $(7,8)$. DEN-induced hepatocarcinoma in animals serves as a standard model to study the beneficial effects of many drugs and treatments on $\operatorname{HCC}(9,10)$. Prior studies have shown the histopathological similarities of human HCC and chemical-induced experimental liver tumors in Wistar rats and Syrian golden hamsters (11). The purpose of this study was to define the characterization of DEN-induced liver carcinogenesis in Syrian golden hamsters.

\section{Materials and methods}

Chemical reagents. DEN was purchased from Sigma (St. Louis, MO, USA) and freshly diluted in saline to a final concentration before use.

Animals. A total of 36 male Syrian hamsters (Slike Experimental Animal Company, Shanghai, China) at 3 weeks of age and weighing 75-100 g, were housed in accordance with the institutional guidelines for animal experimentation and maintained under standard laboratory conditions with a room temperature of $23 \pm 2^{\circ} \mathrm{C}$, relative humidity of $60 \pm 5 \%$ and a $12 \mathrm{~h} / 12 \mathrm{~h}$ light/dark cycle. All animals were fed with a standard diet and water ad libitum.

The hamsters were divided into two groups. Hamsters $(n=12)$ injected with normal saline and who drank distilled water were used as control. Model hamsters $(n=24)$ received DEN. DEN was injected subcutaneously twice per week for 15 weeks, followed by withdrawal and normal feeding at 16-24 weeks. From 25 to 40 weeks, DEN was added to the drinking water with an initial concentration of $0.05 \mathrm{~g} / \mathrm{l}$ at 
$\mathbf{A}$
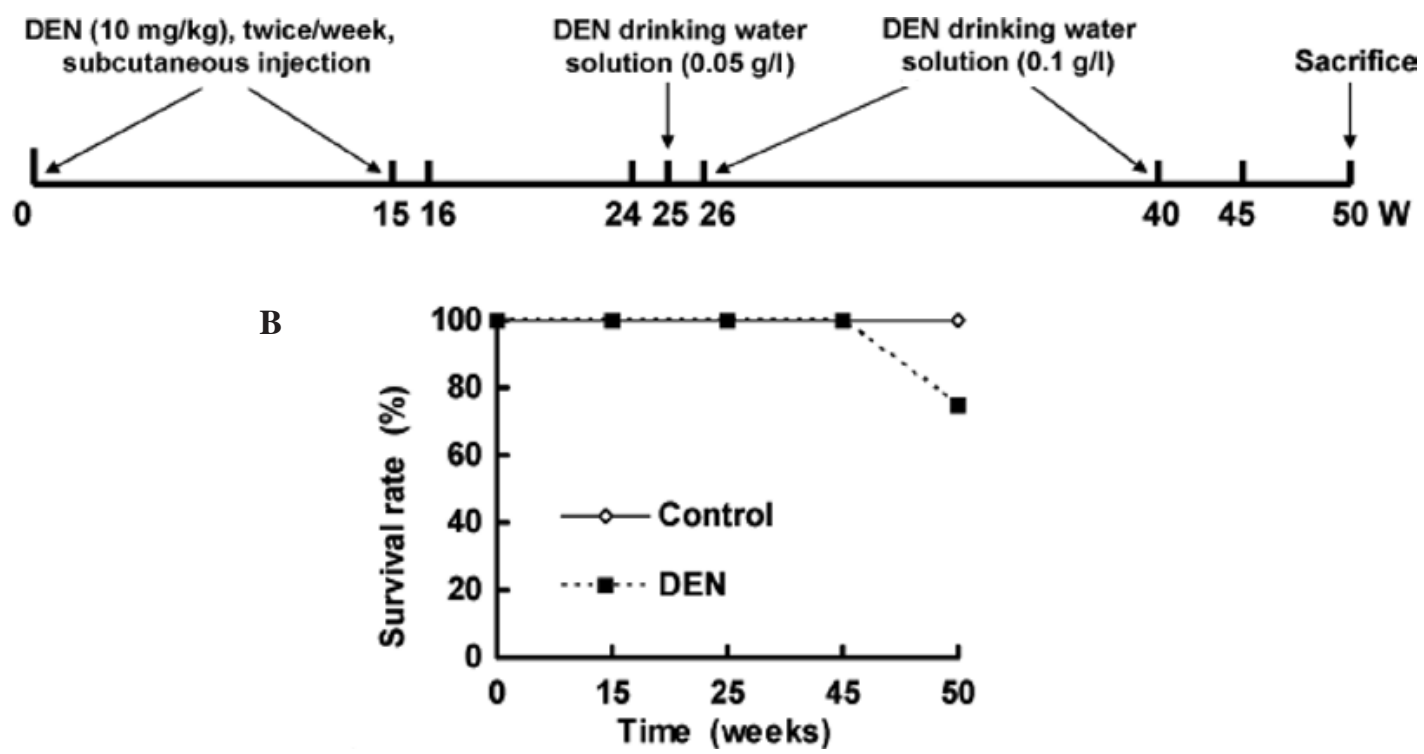

Figure 1. (A) Study protocol and (B) survival rates of the Syrian hamster.

26 weeks and a final concentration of $0.1 \mathrm{~g} / 1$ until 40 weeks. Normal drinking resumed from 41 to 50 weeks (Fig. 1A). Two animals from each group were sacrificed at 15, 24 and 45 weeks for histopathological examination. All hamsters were sacrificed by the end of 50 weeks (Fig. 1A).

Histopathological examination. Animals were weighed weekly during the treatment period and monthly thereafter. At the end of the 50th week, all surviving animals were sacrificed with $1 \%$ sodium pentobarbital. Liver, lung, spleen, kidney and heart were examined grossly and microscopically for DEN-induced tumorigenicity. The organs were fixed in $10 \%$ phosphate-buffered formalin and processed for histological examination with H\&E staining. H\&E-stained sections from multiple paraffin blocks (16 per animal) for each period were examined by light microscopy. All nodular lesions were diagnosed histopathologically and counted using serial sections.

Immunohistochemical staining. Tissues were fixed in $10 \%$ phosphate-buffered formalin and processed for $\alpha$-fetoprotein (AFP) (Envison kit; Maixin-Bio Company, Fuzhou, China). AFP immunostaining was performed according to the steps described in the operational manuals. Dilution of the primary antibody was 1:50. Human AFP-positive HCC tissue served as the positive control, while the negative control was diluted with normal mouse serum in PBS solution as a replacement for the primary antibody control.

Cell culture and tumor transplantation. The isolated tissue was immediately minced $\left(1 \mathrm{~mm}^{3}\right)$ by scalpel under sterile conditions and incubated with $1 \mathrm{mg} / \mathrm{ml}$ collagenase IV (C5138; Sigma) for $30 \mathrm{~min}$ at $37^{\circ} \mathrm{C}$ under gentle agitation (Sanyo, Japan) as previously described (12). Next, the cells were passed through a 200 -mesh screen and washed twice before spinning at $1,500 \mathrm{rpm}$ for $5 \mathrm{~min}$ at $4^{\circ} \mathrm{C}$. Cells were cultured in a culture flask (Corning) in DMEM/F12 medium (Hyclone, Beijing, China) with the addition of $10 \%$ fetal bovine serum (Gibco), $100 \mathrm{IU} / \mathrm{ml}$ penicillin (Amresco) and $50 \mu \mathrm{g} / \mathrm{ml}$ streptomycin
(Amresco). The cell culture was monitored with phase contrast microscopy.

Tumor tissue with high proliferating activity was selected under sterile conditions, rinsed with iced normal saline three times and cut into small pieces of $1 \times 1 \mathrm{~mm}$ for xenografts. Under direct vision through surgery, a small piece of tumor tissue prepared within $2 \mathrm{~h}$ was inoculated in the left lobe of the liver of male Syrian hamster, and sutured and disinfected conventionally. Caesarean section was performed for observation at 7 and 10 days after transplantation (Nikon ECLIPSE TS100).

Statistical analysis. All of the data were processed by statistical software SPSS 16.0. Results were expressed as the means \pm SE. Statistical analysis was tested using one-way analysis of variance. Differences were considered to denote statistical significance at two-tailed $\mathrm{p}<0.05$.

\section{Results}

Macronodular hepatocellular carcinoma in Syrian hamsters. Fig. 1B shows the survival rate of hamsters. A total of 6 animals treated with DEN died between 45 and 50 weeks, whereas unexpected death was not observed in the control hamsters.

No tumors were observed in the control animals. The gross pathological findings of DEN-treated livers included ascites, hepatomegaly, small hepatic cysts and multiple hepatic nodules. Gross examination at 45 and 50 weeks of the DEN treatment demonstrated macronodular HCC in $33.3 \%(4 / 12)$ of the DEN-treated Syrian hamsters (Fig. 2). The livers with $\mathrm{HCC}$ were enlarged with multiple small nodules of $0.2-0.5 \mathrm{~cm}$ in diameter (Fig. 2A-D), or with a single large nodule of $3 \mathrm{~cm}$ in diameter (Fig. 2E). Light microscopy and H\&E staining showed nodular HCC (Fig. 3A). There were frequent bizarre neoplastic cells and abnormal mitotic figures (Fig. 3B). In addition, the HCC nodules were accompanied by chronic inflammatory infiltrates (Fig. 3A) and separated by cords of atrophic hepatocytes (Fig. 3A). 


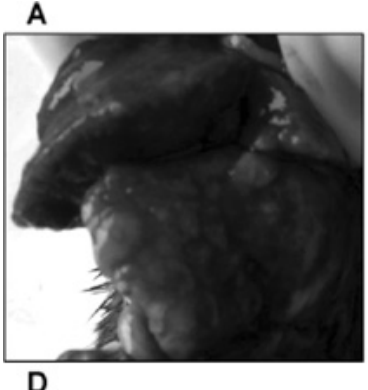

D

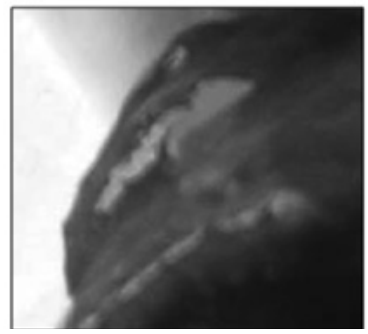

B

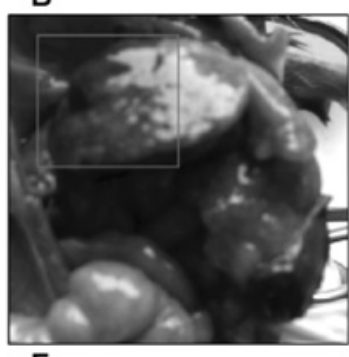

E

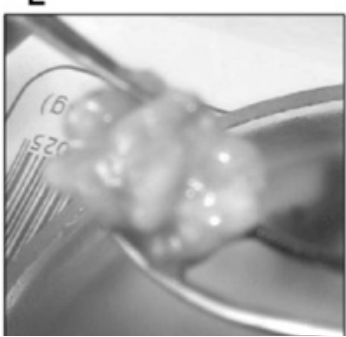

C

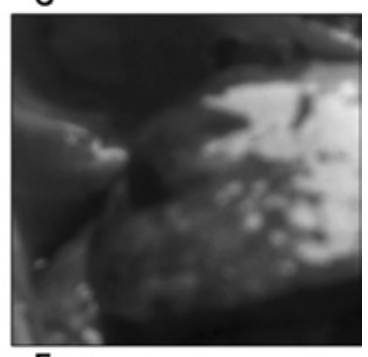

$\mathbf{F}$

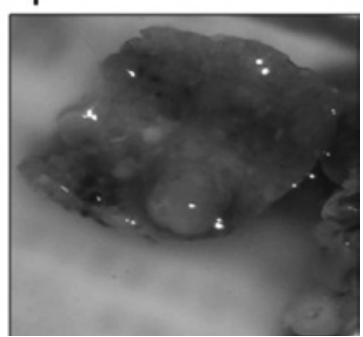

Figure 2. Gross examination of macronodular hepatocellular carcinoma. The livers were replaced by many macronodules (A, B, E and F) and isolated hematoma (A-D). C and D are magnified images of A and B. Syrian golden hamsters were treated with DEN and then sacrificed at 50 weeks.
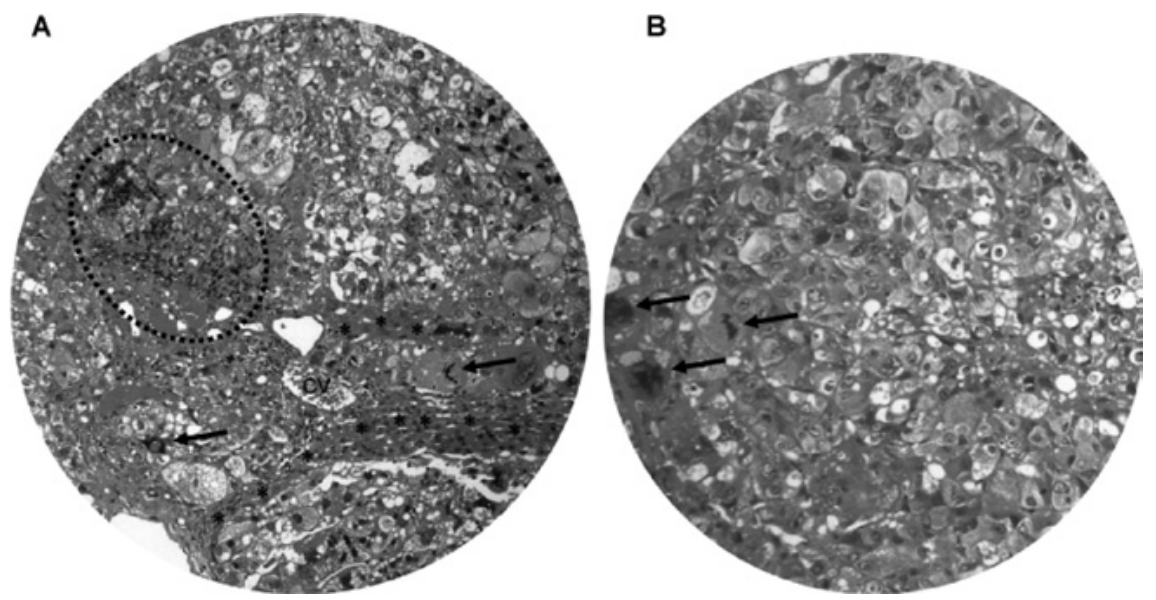

Figure 3. Light microscopy of macronodular hepatocellular carcinoma. (A) H\&E staining demonstrates the nodular appearance of HCC with frequent bizarre cells and mitotic figures (A and B, arrows). The tumor nodules are accompanied by chronic inflammatory infiltrates (dashed circle) and separated by cords of condensed residual hepatocytes ("). cv, central vein. Original magnification: A, x200; B, x400.
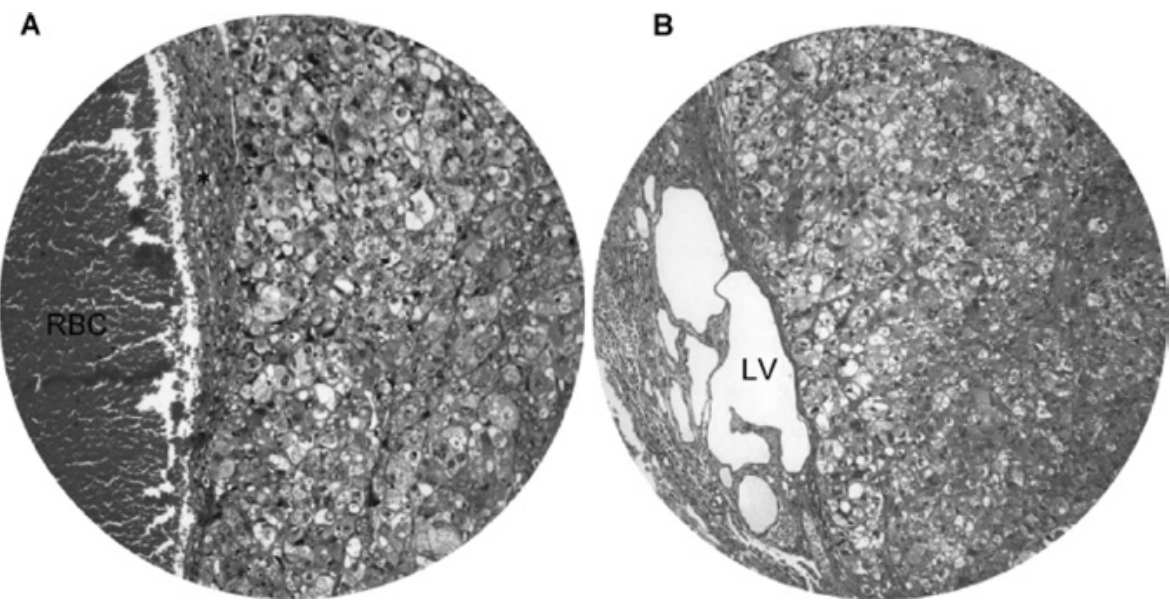

Figure 4. Invasiveness of macronodular hepatocellular carcinoma. Invasion of (A) blood vessels and (B) lymph vessels (LV) by HCC was evident in hamsters treated with DEN for 45 weeks. The blood vessels showed congestion (red blood cells; RBC), whereas the lymph vessels were markedly dilated with multiple cystic changes. Original magnification, x200. 


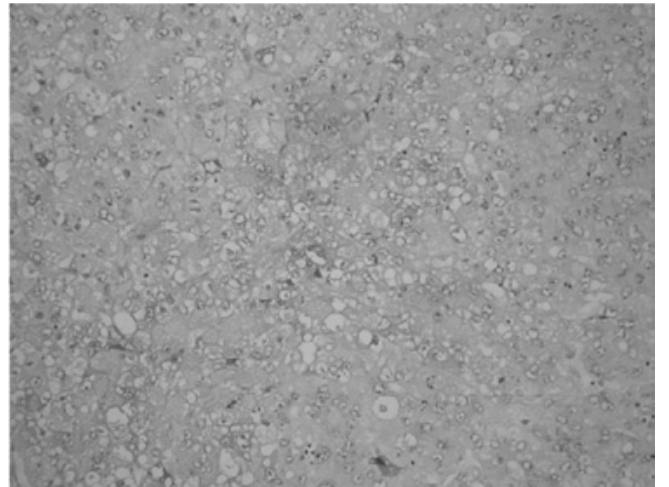

Figure 5. Immunostaining of AFP in macronodular hepatocellular carcinoma. Less than one-third of the HCC cells were positive for AFP and the immunoreactivity was localized in the cytoplasm and membrane. Original magnification, $\mathrm{x} 200$.

We also observed the invasiveness of macronodular HCC (Fig. 4). Invasion of blood vessels (Fig. 4A) and lymph vessels (Fig. 4B) by HCC was evident in hamsters treated with DEN for 45 weeks and onwards. The blood vessels showed congestion, whereas the lymph vessels were markedly dilated with multiple cystic changes. Immunohistochemical staining revealed that approximately one-third of the HCC cells were positive for AFP (Fig. 5), and the immunoreactivity was localized in the cytoplasm and membrane.

Primary cell culture and tumor transplantation. The use of primary cultures from tumor cells is a promising approach for the development of new methods for the diagnostics and therapy of cancer. Fig. 6 illustrates the cultured HCC cells on day 1 (Fig. 6A), day 3 (Fig. 6B) and day 7 (Fig. 6C and D). Clone expansion and confluence was time-dependent in this primary cell culture.

Pre-neoplastic changes in the liver. Changes in the DEN-treated livers in addition to HCC were chronic inflammatory cell infiltrates, fatty metamorphosis, ballooning degeneration, focal eosinophilic necrosis, hyperplastic nodules and multilocular cysts (Figs. 7-10). Cirrhosis and dilatation of the common bile duct were not observed in any animals.

From 15 weeks onward, DEN-treated animals showed chronic inflammatory infiltrates, dilated lymph vessels and proliferating bile ducts in the portal area (Fig. 7A). In addition, fatty change and clustering of proliferative bile ducts were found adjacent to the central vein (Fig. 7B). Hepatocytes in the DEN-treated hamsters also underwent degenerative changes, such as nuclear vacuolation, ballooning degeneration (Fig. 7C) and eosinophilic necrosis (Fig. 7D).

Nodular hyperplasia and hyperplastic nodules were encountered in the hamsters at 16-24 weeks of the DEN treatment (Fig. 8). The size of the nodular lesions varied from a pinpoint to $1.5 \mathrm{~cm}$ in diameter. The nodular lesions included patches of clear cell hyperplasia coexisting with dilated blood vessels (Fig. 8A), focal clear cell hyperplasia accompanying proliferating bile ducts and chronic inflammatory cells adjacent to the central vein (Fig. 8B), and well-defined nodular hyperplasia arising from the background of chronic inflammation and hepatocyte degeneration (Fig. 8C). In addition, clear
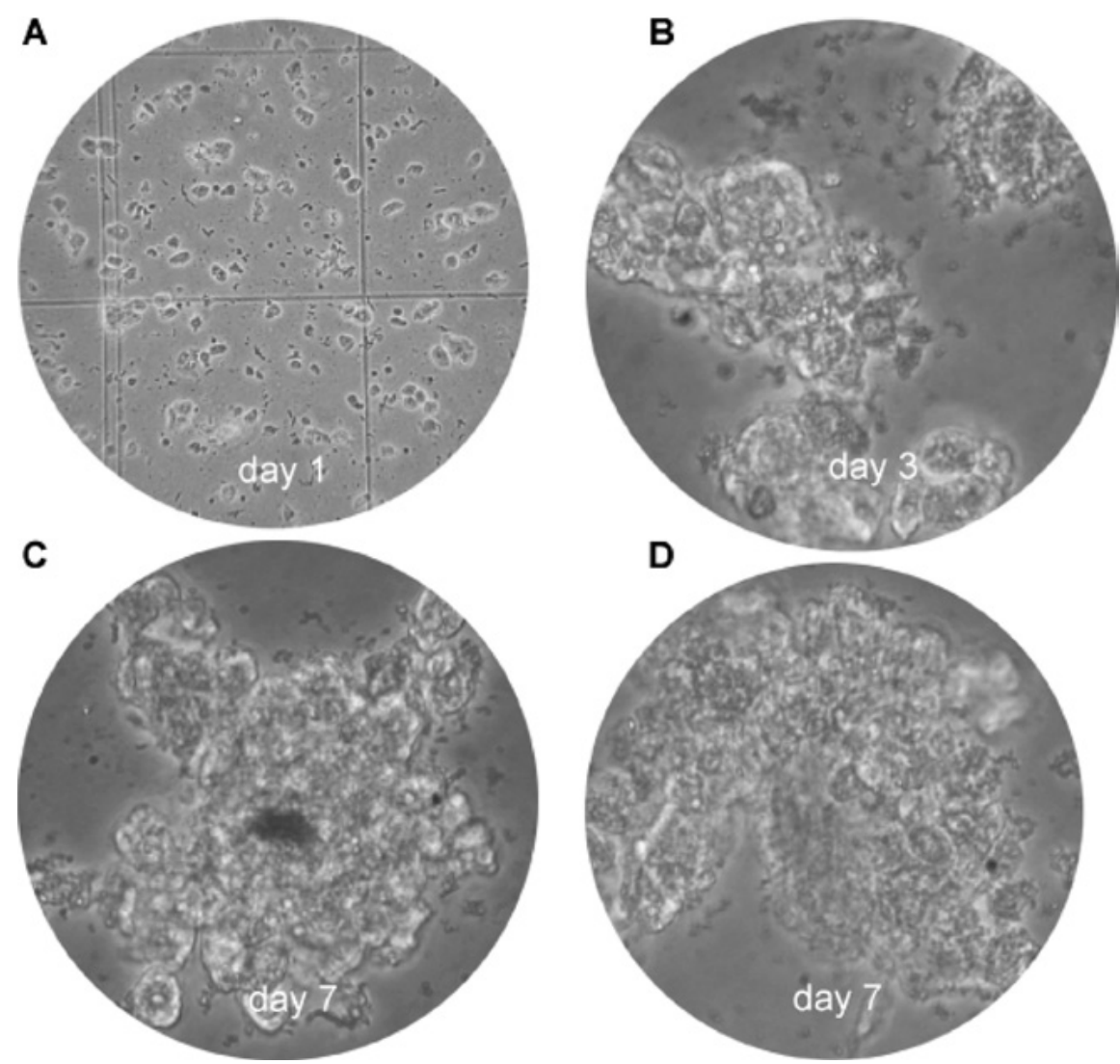

Figure 6. Primary cell cultures of HCC. (A) Cultured HCC cells on day 1, (B) on day 3 and (C and D) on day 7. Original magnification: A, x40; B-D, x400. 

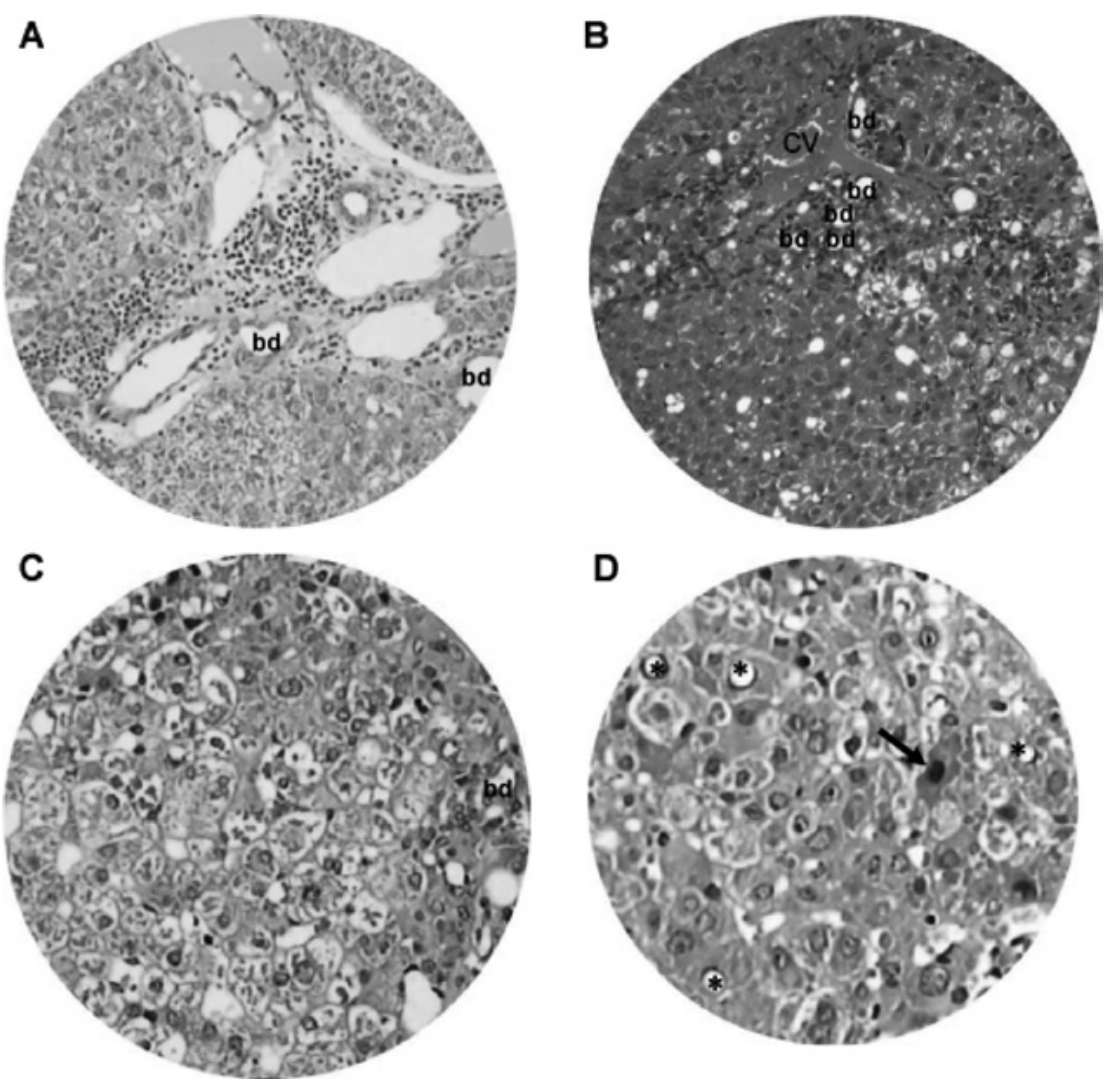

Figure 7. Chronic inflammation and hepatocyte degeneration. Light microscopy of H\&E-stained liver tissue sections revealed chronic inflammation and dilated vessels and/or bile ducts (bd) in regions of the (A) portal area and (B) central vein (cv). (C and D) Hepatocytes underwent nuclear vacuolation $(*)$, ballooning degeneration and eosinophilic necrosis (arrow). Original magnification: A and B, x200; C and D, x400.

A

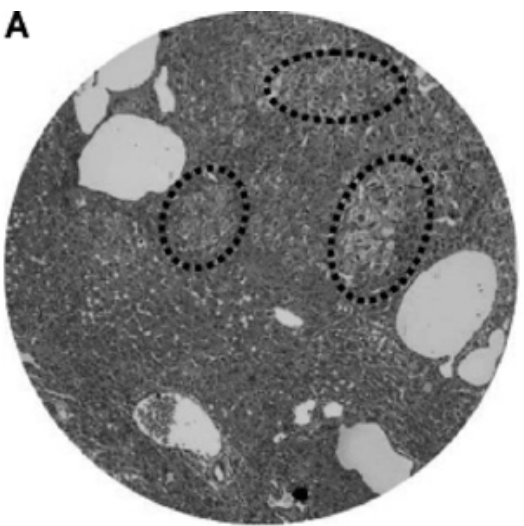

C

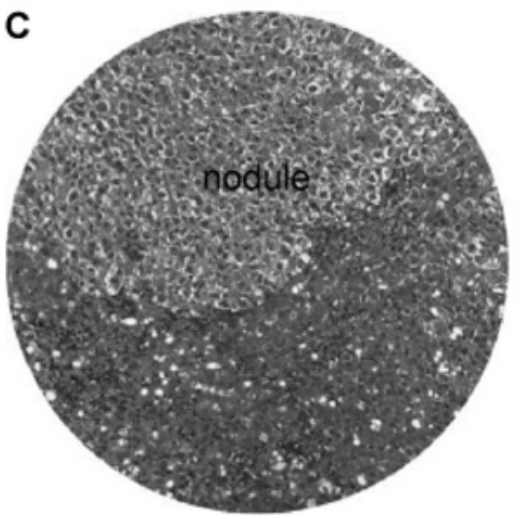

B

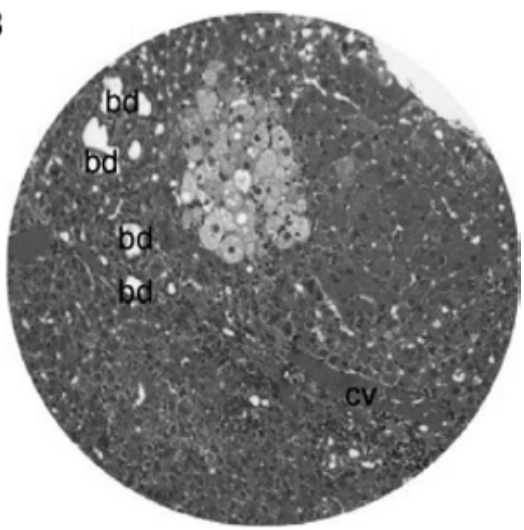

D

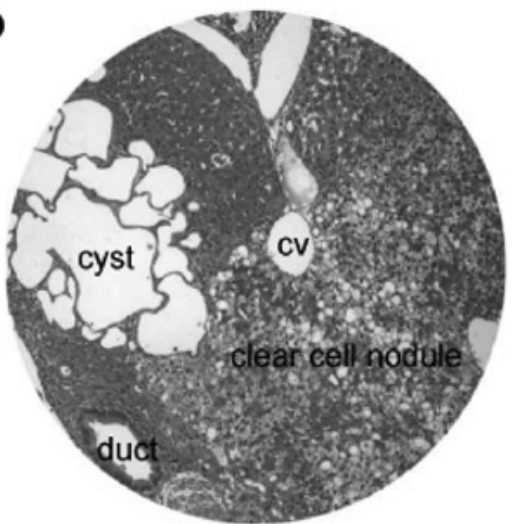

Figure 8. Liver nodular hyperplasia and hyperplastic nodules. (A) Patches of clear cell hyperplasia (dash circle) coexisting with dilated blood vessels. (B) Focal clear cell hyperplasia accompanying dilated bile ducts (bd) and chronic inflammation adjacent to the central vein (cv). (C) Well-defined nodular hyperplasia (nodule) arising from chronic inflammation and hepatocyte degeneration. (D) Clear cell nodule and focal clustering of microcysts. H\&E staining; original magnification, $\mathrm{x} 200$. 

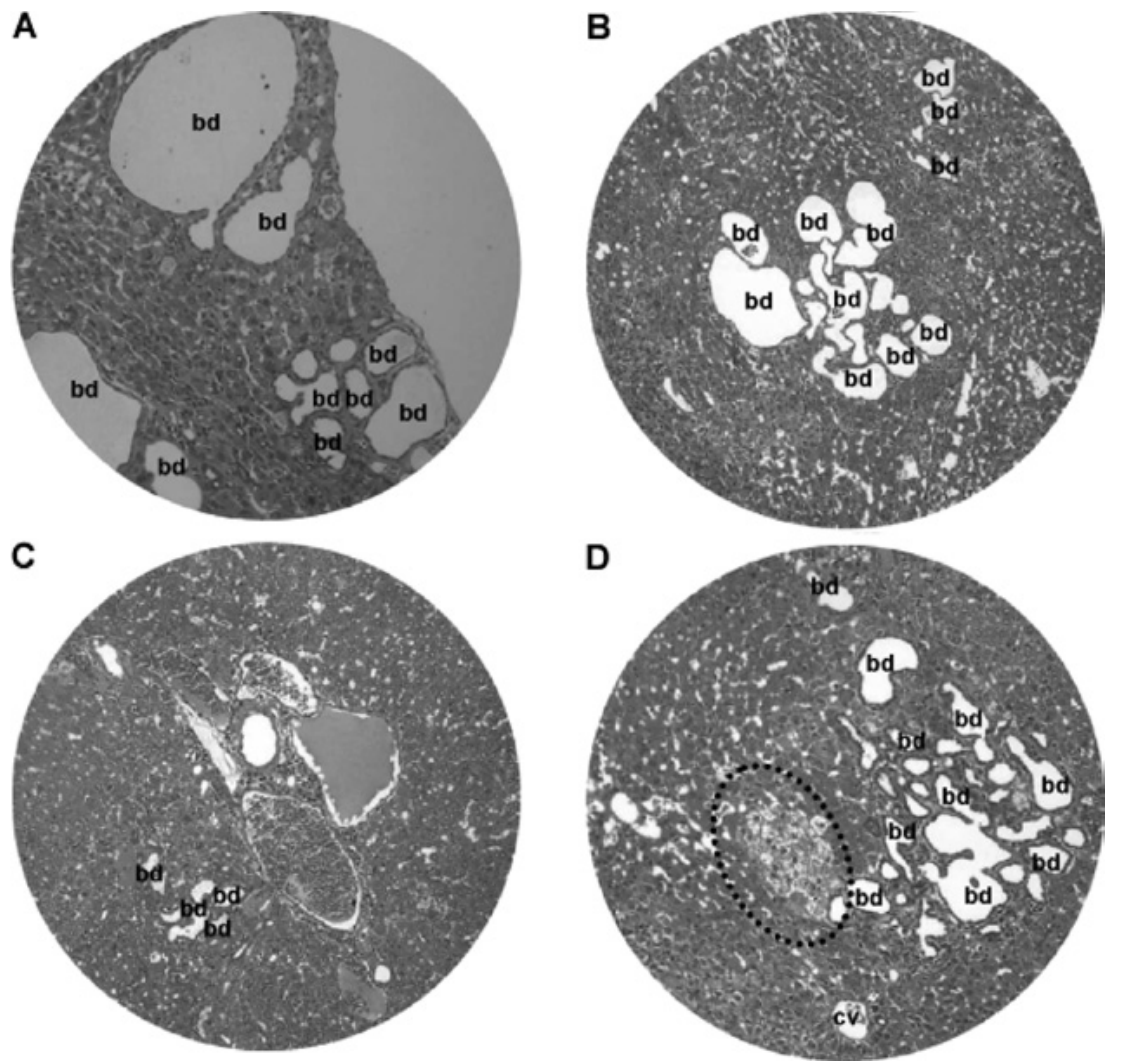

Figure 9. Bile duct dysplasia. Focal bile duct (bd) dysplasia with marked dilation and (A) cystic formation, (B) fatty changes, (C) congestion and (D) clear cell hyperplasia (dashed line circle). cv, central vein. H\&E staining; original magnification, x200.
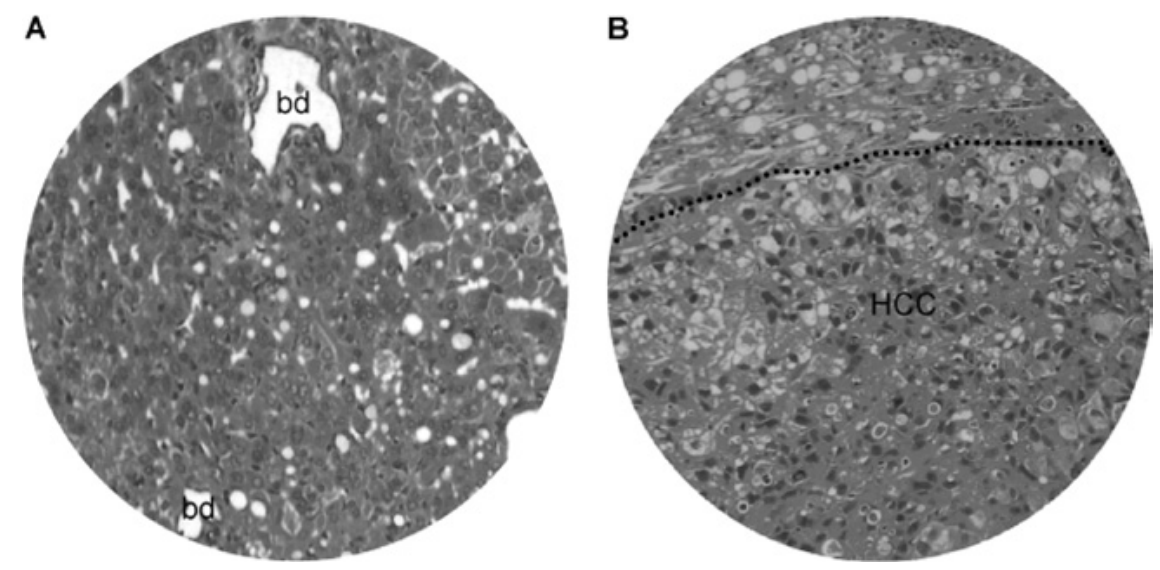

Figure 10. Liver fatty changes. (A) Fatty changes in non-neoplastic liver with dilated bile ducts (bd). (B) Fatty changes in both non-neoplastic liver (above dashed line) and neoplastic lesion (HCC, below dashed line). Original magnification, x200.

cell nodules and focal clustering of microcysts often existed (Fig. 8D).

At 25-50 weeks of the DEN treatment, there were focal bile duct hyperplasia (Fig. 9) and fatty changes (Fig. 10) adjacent to HCC lesions. Focal bile duct dysplasia, with marked dilation and cystic formation (Fig. 9A), fatty changes (Fig. 9B), congestion (Fig. 9C) and clear cell hyperplasia (Fig. 9D), often co-existed. Fatty changes were observed in both early (Fig. 10A) and advanced (Fig. 10B) stage of HCC, suggesting an association between fatty metamorphosis and the hepatic carcinogenesis liver.
Lung tumors. Gross and microscopic examination revealed lung tumors in 2/4 hamsters at 25-50 weeks of the DEN treatment. The lung tumor mass was most frequently single rather than multiple, and varied from 0.3 to $1.2 \mathrm{~cm}$ in diameter. Light microscopy and H\&E staining demonstrated welldifferentiated neoplastic cells (Fig. 11A) admixed with chronic inflammatory cell infiltrates (Fig. 11B). The morphology of the neoplastic cells in the lung was different compared to that of HCC. Consistently, immunohistochemistry illustrated that only a few macrophages, but not the neoplastic cells, were positive for AFP (Fig. 12), indicating that the lung tumors 

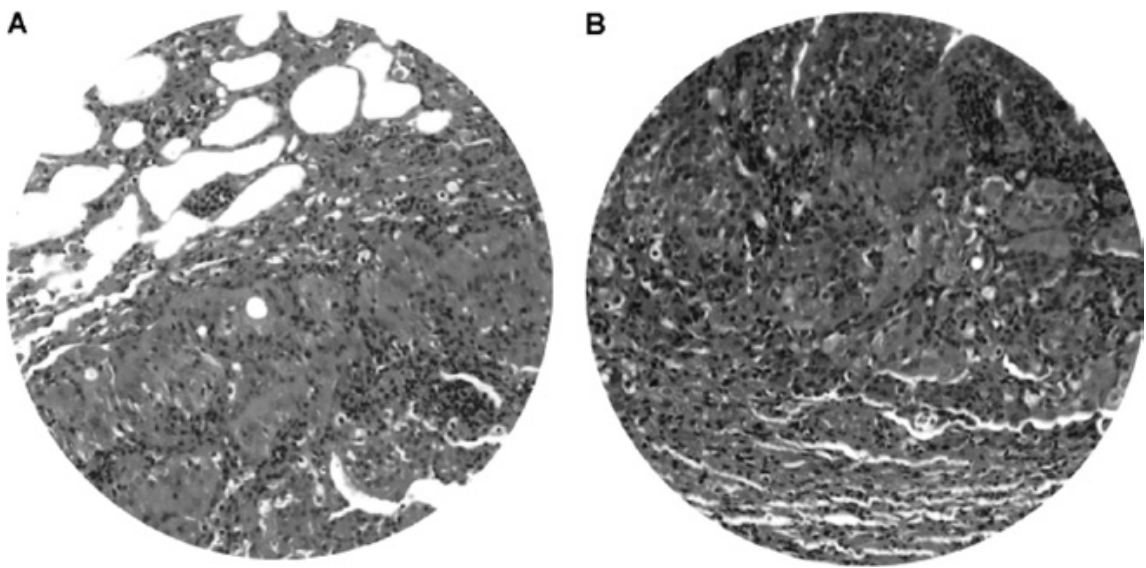

Figure 11. Lung tumor. Light microscopy and H\&E staining demonstrated (A) well-differentiated neoplastic cells admixed with (B) chronic inflammatory infiltrates in lung tumors. Original magnification, x200.

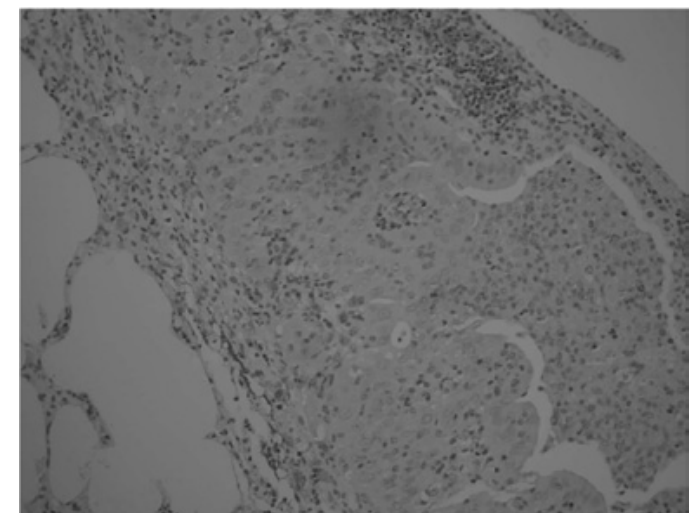

Figure 12. Immunostaining of AFP in lung tumor. A few macrophages surrounding the neoplastic cells were positive for AFP, while no immunoreactivity was found in lung neoplastic cells. Original magnification, $\mathrm{x} 200$.

may not be HCC metastasis. No tumors were detected in the kidney, pancreas, spleen or other anatomical sites.

\section{Discussion}

This study describes the histopathological series of events in hamsters administered DEN. The most important findings were macronodular HCC with a potential for primary cell culture and tumor transplantation, pre-neoplastic lesions that progress to $\mathrm{HCC}$ and primary lung tumors.

$\mathrm{HCC}$ is a highly malignant tumor with poor prognosis $(13,14)$. Advanced HCC is associated with wasting symptoms, such as ascites and weight loss (15). One of the biochemical characteristics of HCC is AFP elevation (16-18). Pre-neoplastic lesions, such as fatty change and nodular hyperplasia, are frequently observed in HCC in both early and advanced stages (19). DEN is an established environmental hepatocarcinogen initially used to induce liver cancer in animal models (20). It has been shown that on primary metabolic activation, DEN produces the promutagenic adducts, $\mathrm{O}^{6}$-ethyl deoxy guanosine and $\mathrm{O}^{4}$ - and $\mathrm{O}^{6}$-ethyl deoxy thymidine that causes DNA-chain damage and miscode gene sequences, paving the way to initiation of liver carcinogenesis $(6,21)$. In DEN-treated hamsters, progressive body weight loss, hepatomegaly, ascites and tumor formation are noted (22). The DEN-induced macronodular HCC was characterized by poor differentiation, AFP immunoreativity, vessel invasion and a potential application for primary cell culture and tumor transplantation. These findings indicate that administration of DEN produces $\mathrm{HCC}$ in hamsters that mimics human HCC (23-28).

Primary human HCC exhibits characteristics, such as arterial phase hypervascularity with portal phase washout, and the presence of fatty degeneration and portal venous invasion. Intrahepatic biliary duct dilatation is well recognized with cholangiocarcinoma and is frequently observed in metastatic HCC (29). HCC is frequently accompanied by dilatation of the intrahepatic bile ducts (30-37), while focal bile duct hyperplasia often occurs in the adjacent non-tumorous liver tissue of European patients (38). In this study, pre-neoplastic lesions, including focal bile duct hyperplasia, fatty change and clear cell hyperplasia, occurred in DEN-induced hepatocarcinogenesis.

In the present study, lung neoplastic cells were morphologically distinct from HCC and had negative AFP reactivity, indicating that the lung tumors were more likely primary lesions rather than metastases. This finding is consistent with an early report that feeding of DEN induces tumors of the lung and liver in rats (39). To our knowledge, this is the first report of lung tumors in DEN-treated hamsters.

In this study, DEN-induced hepatocarcinogenesis progressed over specific periods. A toxic reaction and hepatocyte regeneration occurred in the early stage defined from the 1 st to 15 th week of treatment. This was followed by prominent nodular hyperplasia and fatty changes from 16 to 24 weeks of administration. From 25 to 50 weeks of induction, both micronodular and macronodular HCC occurred. These serial events are consistent with the development of human hepatocarcinogenesis (40), highlighting the potential application of this animal model for HCC research.

In the present study, dose-response effects were not tested, since long-term treatment with DEN results in the substantial loss of animals. On the other hand, the greater susceptibility of animals toward a carcinogenic effect seems well documented, but the underlying mechanism remains undetermined. In summary, DEN induces hepatocarcinogenesis in hamsters and may serve as a new and dynamic animal model for studying the pathogenesis and clinical treatment of hepatocellular carcinoma. 


\section{Acknowledgements}

This study was in part supported by the National Natural Science Foundation of China (no. 30760281), a direct grant from the Guilin Medical College, and by a Guangxi Medical Science Experimental Center open fund for special projects (KFJJ2010-49).

\section{References}

1. Ferlay J, Shin HR, Bray F, Forman D, Mathers C and Parkin DM: Estimates of worldwide burden of cancer in 2008: Globocan 2008. Int J Cancer 127: 2893-2917, 2010.

2. Herszenyi L and Tulassay Z: Epidemiology of gastrointestinal and liver tumors. Eur Rev Med Pharmacol Sci 14: 249-258, 2010

3. Sherman M: Hepatocellular carcinoma: epidemiology, risk factors, and screening. Semin Liver Dis 25: 143-154, 2005.

4. Farazi PA and DePinho RA: Hepatocellular carcinoma pathogenesis: from genes to environment. Nat Rev Cancer 6: 674-687, 2006.

5. Janani P, Sivakumari K, Geetha A, Ravisankar B and Parthasarathy C: Chemopreventive effect of bacoside a on $\mathrm{n}$-nitrosodiethylamine-induced hepatocarcinogenesis in rats. J Cancer Res Clin Oncol 136: 759-770, 2010.

6. Verna L, Whysner J and Williams GM: N-nitrosodiethylamine mechanistic data and risk assessment: bioactivation, DNA-adduct formation, mutagenicity, and tumor initiation. Pharmacol Ther 71: 57-81, 1996.

7. Liu XE, Dewaele S, Vanhooren V, Fan YD, Wang L, van Huysse J, Zhuang H, Contreras R, Libert C and Chen CC: Alteration of n-glycome in diethylnitrosamine-induced hepatocellular carcinoma mice: a non-invasive monitoring tool for liver cancer. Liver Int 30: 1221-1228, 2010.

8. Mandal AK, Das S, Mitra M, Chakrabarti RN, Chatterjee M and Das N: Vesicular flavonoid in combating diethylnitrosamine induced hepatocarcinoma in a rat model. J Exp Ther Oncol 7 : 123-133, 2008

9. Bychkov VG, TrukhanovaLS,Krylov GG, KulikovaLN,Mal'tseva ED, Smirnova EA and Kondalenko VF: N-nitrosodiethylamineinduced changes in the liver of syrian hamster with superinvasive opistorchiasis. Vopr Onkol 49: 476-483, 2003 (In Russian).

10. Simonsen R and Virji MA: Interpreting the profile of liver-function tests in pediatric liver transplants. Clin Chem 30: 1607-1610, 1984.

11. Llombart Bosch A and Peydro Olaya A: Ultrastructure of human hepatic carcinomas compared with ultrastructural findings in hepatomas induced by chemical agents in Wistar rats and the Golden hamster. Rev Esp Oncol 30: 287-302, 1983 (In Spanish).

12. Fluckiger AC, Marcy G, Marchand M, Negre D, Cosset FL, Mitalipov S, Wolf D, Savatier P and Dehay C: Cell cycle features of primate embryonic stem cells. Stem Cells 24: 547-556, 2006.

13. Di Maio M, De Maio E, Perrone F, Pignata S and Daniele B: Hepatocellular carcinoma: systemic treatments. J Clin Gastroenterol 35: S109-S114, 2002.

14. Yu AS and Keeffe EB: Management of hepatocellular carcinoma. Rev Gastroenterol Disord 3: 8-24, 2003.

15. Kwe MC: Tumors of the liver. In: Hepatology - A Text Book of Liver Disease. Zakim D and Boyer TD (eds.). Saunders, Philadelphia, pp1513-1548, 1996.

16. Lokich JJ: Determination of response in treatment of hepatic neoplasia. Semin Oncol 10: 228-237, 1983.

17. Rosi F, Tabucchi A, Carlucci F, Galieni P, Lauria F, Zanoni L, Guerranti R, Marinello E and Pagani R: 5'-nucleotidase activity in lymphocytes from patients affected by B-cell chronic lymphocytic leukemia. Clin Biochem 31: 269-272, 1998.

18. Sell S and Becker FF: Alpha-fetoprotein. J Natl Cancer Inst 60: 19-26, 1978.

19. Kutami R, Nakashima Y, Nakashima O, Shiota K and Kojiro M: Pathomorphologic study on the mechanism of fatty change in small hepatocellular carcinoma of humans. J Hepatol 33 . 282-289, 2000

20. Kawabe M, Lin C, Kimoto N, Sano M, Hirose M and Shirai T: Modifying effects of propolis on MeiQx promotion of rat hepatocarcinogenesis and in a female rat two-stage carcinogenesis model after multiple carcinogen initiation. Nutr Cancer 37: $179-186,2000$
21. Dagli MLZ: Agentes antineoplasicos. In: Farmacologia Aplicada á Medicina Veterinaria. 3rd edition. Spinosa HS, Gorniak SL and Bernardi MM (eds.). Editora Guanabara-Koogan, São Paulo, Brasil, pp577-608, 2002.

22. Pitot HC, Campbell HA, Maronpot R, Bawa N, Rizvi TA, Xu YH, Sargent L, Dragan Y and Pyron M: Critical parameters in the quantitation of the stages of initiation, promotion, and progression in one model of hepatocarcinogenesis in the rat. Toxicol Pathol 17: 594-612, 1989.

23. Kalinski T and Roessner A: Hepatocellular carcinoma: pathology and liver biopsy. Dig Dis 27: 102-108, 2009.

24. Prasad SR, Wang H, Rosas H, Menias CO, Narra VR, Middleton WD and Heiken JP: Fat-containing lesions of the liver: radiologic-pathologic correlation. Radiographics 25: 321-331, 2005.

25. Roskams T and Kojiro M: Pathology of early hepatocellular carcinoma: conventional and molecular diagnosis. Semin Liver Dis 30: $17-25,2010$.

26. Sakamoto M, Hirohashi S and Shimosato Y: Early stages of multistep hepatocarcinogenesis: adenomatous hyperplasia and early hepatocellular carcinoma. Hum Pathol 22: 172-178, 1991.

27. Shirabe K, Motomura T, Muto J, Toshima T, Matono R, Mano Y, Takeishi K, Ijichi H, Harada N, Uchiyama H, Yoshizumi T, Taketomi A and Maehara Y: Tumor-infiltrating lymphocytes and hepatocellular carcinoma: pathology and clinical management. Int J Clin Oncol 15: 552-558, 2010.

28. Villanueva A, Hoshida Y, Battiston C, Tovar V, Sia D, Alsinet C, Cornella H, Liberzon A, Kobayashi M, Kumada H, Thung SN, Bruix J, Newell P, April C, Fan JB, Roayaie S, Mazzaferro V, Schwartz ME and Llovet JM: Combining clinical, pathology, and gene expression data to predict recurrence of hepatocellular carcinoma. Gastroenterology 140: 1501-1512, 2011.

29. Jhaveri KS, Halankar J, Aguirre D, Haider M, Lockwood G, Guindi $\mathrm{M}$ and Fischer S: Intrahepatic bile duct dilatation due to liver metastases from colorectal carcinoma. AJR Am J Roentgenol 193: 752-756, 2009.

30. Jinzaki M, Tanimoto A, Suzuki K, Seki T, Satoh Y, Hiramatsu K, Mukai M and Nakanishi I: Liver metastases from colon cancer with intra-bile duct tumor growth: Radiologic features. J Comput Assist Tomogr 21: 656-660, 1997.

31. Kojiro M, Kawabata K, Kawano Y, Shirai F, Takemoto N and Nakashima T: Hepatocellular carcinoma presenting as intrabile duct tumor growth: a clinicopathologic study of 24 cases. Cancer 49: 2144-2147, 1982.

32. Lee NW, Wong KP, Siu KF and Wong J: Cholangiography in hepatocellular carcinoma with obstructive jaundice. Clin Radiol 35: 119-123, 1984.

33. Okano K, Yamamoto J, Moriya Y, Akasu T, Kosuge T, Sakamoto M and Hirohashi S: Macroscopic intrabiliary growth of liver metastases from colorectal cancer. Surgery 126: 829-834, 1999.

34. Okano K, Yamamoto J, Okabayashi T, Sugawara Y, Shimada K, Kosuge T, Yamasaki S, Furukawa $\mathrm{H}$ and Muramatsu Y: Ct imaging of intrabiliary growth of colorectal liver metastases: a comparison of pathological findings of resected specimens. Br J Radiol 75: 497-501, 2002.

35. Soyer P, Sibert A and Laissy JP: Intrahepatic bile duct dilatation secondary to hepatocellular carcinoma: $\mathrm{Ct}$ features in 10 patients. Abdom Imaging 20: 114-117, 1995.

36. Takamatsu S, Teramoto K, Kawamura T, Kudo A, Noguchi N, Irie T, Ochiai T, Kumagai J, Koike M and Arii S: Liver metastasis from rectal cancer with prominent intrabile duct growth. Pathol Int 54: 440-445, 2004

37. van Sonnenberg E and Ferrucci JT Jr: Bile duct obstruction in hepatocellular carcinoma (hepatoma) - clinical and cholangiographic characteristics. Report of 6 cases and review of the literature. Radiology 130: 7-13, 1979.

38. Schaff Z, Hsia CC, Sarosi I and Tabor E: Overexpression of transforming growth factor-alpha in hepatocellular carcinoma and focal nodular hyperplasia from European patients. Hum Pathol 25: 644-651, 1994.

39. Herrold KM and Dunham LJ: Induction of tumors in the syrian hamster with diethylnitrosamine (N-nitrosodiethylamine). Cancer Res 23: 773-777, 1963.

40. Lee CY, Hsu YC, Wang JY, Chen CC and Chiu JH: Chemopreventive effect of selenium and chinese medicinal herbs on n-nitrosobis(2-oxopropyl)amine-induced hepatocellular carcinoma in syrian hamsters. Liver Int 28: 841-855, 2008. 